\title{
Erratum to: Reinforcing the impacts of work release on prisoner recidivism: the importance of integrative interventions
}

\author{
David Weisburd ${ }^{1,2}$ • Badi Hasisi ${ }^{1}$ - Efrat Shoham ${ }^{3}$. \\ Gali Aviv $^{1}$ • Noam Haviv ${ }^{1}$
}

Published online: 16 May 2017

(C) Springer Science+Business Media Dordrecht 2017

\section{Erratum to: J Exp Criminol \\ DOI 10.1007/s11292-017-9285-3}

In the original version of this article, some errors were retained in copy-editing. Those errors are mentioned below.

Footnote 2: insert "a" before "high proportion of drop outs"

Page 10, 2nd paragraph: Insert ")" after "cantina"

Page 12, last sentence of the 2nd paragraph: "higher than the effects noted" should be changed to "higher than the average effect noted"

Table 2 footnote: Add “**** $p<.001$ ”

Figures 1 and 2: Insert "yr" to every after "Group," and "Release,"

Page 15, last sentence of the 2nd paragraph: "into the treatment group and comparison groups." should be changed to "into the treatment and comparison groups."

The original article was corrected.

The online version of the original article can be found at doi: http://dx.doi.org/10.1007/s11292-017-9285-3

Badi Hasisi

Badi.hasisi@mail.huji.ac.il

1 Institute of Criminology, Faculty of Law, Hebrew University, Jerusalem, Israel

2 Department of Criminology, Law and Society, Center for Evidence-Based Criminology, George Mason University, Fairfax, USA

3 Ashkelon Academic College, Ashkelon, Israel 